\title{
Evaluation of Drug Affordability in Khartoum State, Sudan
}

\author{
Salah Mohamed Elhassan ${ }^{1,2}$, Gamal Osman Elhassan ${ }^{1,3,4 *}$, Abubakr A Alfadl ${ }^{3}$, Sara Anas Sirelkhatim ${ }^{4}$ and Khalid Omer Alfarouk \\ ${ }^{1}$ Sudan National Medical Specialization Board, Khartoum, Sudan \\ ${ }^{2}$ National Medicines and Poisons Board, Ministry of Health, Khartoum, Sudan \\ ${ }^{3}$ Unaizah Pharmacy College (UCP), Qassim University, Alqassim, Kingdom of Saudi Arabia \\ ${ }^{4}$ Department of Pharmacy, Omdruman Islamic University, Omdruman, Khartoum, Sudan \\ ${ }^{5}$ Department of Pharmacy, Alneilain University, Khartoum, Sudan
}

\begin{abstract}
Introduction: Medicine prices are often high and unaffordable not only for the majority of people in low- and middleincome countries, but also for significant number of the population without social protection or insurance in high income countries. As a result, the lack of access to essential medicines due to unaffordability in developing countries is one of the most pressing global health problems.
\end{abstract}

Objective: To provide comparable, evidence-based information for policy makers.

Method: A cross sectional descriptive survey study was applied.

Results and discussion: It seems that despite of the affordability was shown for many studied conditions, but still affordability of medicines remains a major problem for Sudan.

Conclusion: It could be concluded that absence of standard treatment guidelines that are of sound scientific bases and cost-effectiveness resulting in low quality prescribing and dispensing practices which had led to wide variations in the prescribing patterns for the assessed acute and chronic conditions.

\section{Introduction}

Globally, budgets allocated for medicines are high. This clearer in developing countries where budget allocated for medicines accounts for a relatively large portion of total healthcare costs [1-6] estimated at about $20-60 \%$ of health spending [4], compared with $18 \%$ in developed countries [7]. Also, medicine prices are often high and unaffordable not only for the majority of people in low- and middle-income countries, but also for significant number of the population without social protection or insurance in high income countries [1,2]. This problem is even harder in developing countries where up to $90 \%$ of the population purchase medicines through out-of-pocket payments $[8,9]$, making medicines the largest family expenditure item after food. As a result, the lack of access to essential medicines due to unaffordability in developing countries is one of the most pressing global health problems.

Majority of people in developing countries do not have health insurance [10]. At the same time, medicines provided free through the public sector are often unavailable [6]. Consequently, in developing countries medicines are often paid for out of pocket at the time of illness. As a result, where medicine prices are high, people may not afford purchase them and therefore forgo treatment or they may go into debt. For this reason, the World Health Organization (WHO) has designated affordable prices, together with other determinants, as a determinant of access to medicines [11]. In addition, since mid of the last century, several international treaties have established access to healthcare as a human right $[12,13]$. This made availability and affordability of drugs for consumers a public health concern. However, many factors influence whether poor people can obtain affordable drug of good quality. In this regard, medicines prices and individual income are main factors; in addition to out-of-pocket payments for drugs are major contributors to the devastating effects of illness [14].

In 1992, the government of Sudan adopted a number of health policy reforms as part of its programme of economic reforms. As a result, a law was passed that medicines are not any more free-of-charge in public sector health facilities $[15,16]$. Since then, the out-of-pocket became the main source of drug finance as the majority of Sudan population has no health insurance [17]. Some sources estimate that $30 \%$ of the total populations are covered by a public health service, public health insurance or social insurance, or other sickness funds [18]. On other hand, though there are no national estimates on access to medicines in Sudan, but estimates for expenditure by Khartoum state households on drugs suggest that they account for $58 \%$ of total household expenditure on health care. If this taken in connection with the fact that poverty in Sudan is widely spread, and estimated to be above $50 \%$ [19], it becomes necessary to investigate medicines affordability in Sudan. Authors were motivated by this information to measure affordability of basic pharmaceutical treatment as an indicator of access to essential medicines in public and private sector in Khartoum state.

To provide comparable, evidence-based information for policy makers, a survey to measure the affordability of the actual costs of treatment of the ten leading causes of deaths in Khartoum state hospitals [20] was undertaken.

\section{Method}

A cross sectional descriptive survey study was applied. The methodology developed by the World Health Organization and Health Action International [21] for assessing medicine price, availability,

*Corresponding author: Gamal Osman Elhassan, Unaizah College of Pharmacy, Qassim University, Unaizah-Alqassim, Kingdom of Saudi Arabia, Tel: 00966530965955; E-mail: go.osman@qu.edu.sa,gamaosma63@yahoo.com

Received: January 09, 2016; Accepted January 19, 2016; Published January 24, 2016

Citation: Elhassan SM, Elhassan GO, Alfadl AA, Sirelkhatim SA, Alfarouk KO (2016) Evaluation of Drug Affordability in Khartoum State, Sudan. J Pharmacovigilance 4: 191. doi:10.4172/2329-6887.1000191

Copyright: @ 2016 Elhassan SM et al. This is an open-access article distributed under the terms of the Creative Commons Attribution License, which permits unrestricted use, distribution, and reproduction in any medium, provided the original author and source are credited. 
and affordability was used in this study with slight modification. That was done through a measure of actual costs of treatment of selected diseases from patients leaving the health facilities after they had been treated and received their drugs either from the same health facility or the closest drug out let.

Medicine affordability has been investigated in terms of the days' wages that a country's lowest paid unskilled government worker (LPGW) needs to spend on a standard course of treatment $[6,11]$. Although this method has the limitation that it does not provide insight into the affordability of medicines for the often large sections of the population that earn less than the LPGW $[6,22]$, but still it is the most reliable method. Therefore, affordability in this study is expressed as the number of days the lowest paid unskilled government worker would have to work in order to afford the cost of therapeutic course of treatment for infectious and chronic diseases and for one month of treatment for the chronic condition being analyzed [19]. The daily wage of the lowest-paid unskilled government worker in the analysis was 15.13 SD (Sudanese Dinars) which is the monthly salary for the lowest governmental worker (454 SD) divided by thirty.

\section{Sampling}

A systematic sampling method was used to select medicine outlets. Khartoum state was stratified into five geographical areas. In each area, the main general public hospital and the health centre located in the most rural or lowest income-generating area were chosen as the sampling site. Thirteen other public health facilities (small hospitals and large health centres) were also selected to complete the number to fifteen from each area. These public health facilities catered to outpatients and they have pharmacies or medicine-dispensing areas were chosen. Medicine prices are collected from either the public, where patients are charged for medicines, or the closest private drug out let to the selected health facilities where the prescribed medicine (s) is (are) available.

\section{Selection of medicines to be studied}

Medicines were chosen purposively based on national disease patterns and statistic status in Sudan [20]. These relate to both acute and chronic common conditions causing significant morbidity and mortality. The core list medicines were selected on the basis of the disease burden including the top ten leading causes of deaths in Khartoum state hospitals in 2010, the top ten leading causes of hospital admissions, and the top ten diseases treated in outpatient clinics (Table 1). From this official data seven diseases are selected for the survey. These are: adult moderate pneumonia, paediatric moderate pneumonia, paediatric acute bronchitis, adult acute tonsillitis, type 2 diabetes, asthma, and hypertension. Drug key-list to compare the prescribed medicines was chosen in accordance to WHO model list [23] to assess drug affordability concerning the selected diseases in the selected health facilities.

\section{Data collection}

Trained data collectors, who were pharmacy students in their fourth year of their graduation, have visited medicine outlets and recorded data on a standardized form. Data collection form contained all demographic characteristics of patients, in addition to, medicines' prices, doses, strengths and amount of medicines prescribed per week or month. The unit prices were calculated and checked at the end of each day of data collection. Data consisted of all patients visited the fifteen public health facilities selected from the seven chosen localities in the period of data collection (from10/11 to 18/11/2012) that fulfill the selection criteria of having the selected disease and have their medicines dispensed from the health facility or the nearby drug out let.

As price of the same branded medicine should be uniform overall public and private health facilities according to the regulations by the National Medicines and Poisons Board (NMPB), the medicine regulatory authority (MRA) of the Sudan, authors concentrate on the actual total cost of treatment rather than the hypothetical price of a selected basket of medicines that may not be prescribed or dispensed.

\section{Data analysis}

Affordability was assessed as the number of days' wages the lowest paid un-skilled government worker would have to earn to purchase one course of treatment for infectious diseases, or for one month of treatment for the chronic condition being analyzed [19]. The daily wage of the lowest-paid unskilled government worker in the analysis was 15.13 SDG (2.48 US Dollar) which is the monthly salary for the lowest government worker (454 SDG (74.55 US Dollar)) divided by thirty.

\section{Results}

Data for assessing affordability was collected from fifteen public health facilities selected from seven localities in Khartoum state. The affordability of treatment was estimated as the number of days' wages the lowest-paid government worker would be required to pay to purchase from the public/private sector a full course (for infectious disease) or a one-month course (for chronic disease) of medicine at the standard or common dose as shown in Table 1. The salary of the lowest paid regular government worker was Sudanese Pound (SDG) 454 (74.55 US Dollar) (2015) per month or 15.13 SDG (2.48 US Dollar) per day. The cost of treatment and affordability of the seven selected conditions is shown in Figure 1.

\section{Discussion}

This study showed that many of treatments for conditions studied are affordable. One example is the case of amoxicillin $500 \mathrm{mg}$ to treat acute adult pneumonia and other respiratory infection, a common problem in developing countries. From this study, the lowest priced generic of amoxicillin $500 \mathrm{mg}$ with five days to one week's treatment regimen of an episode of acute respiratory infection in adults had to be paid less than one day's salary which is affordable for unskilled government worker when purchased from public sector or private sector ( 0.53 and 0.66 days' wages respectively). This finding complied with the results of studies conducted to investigate affordability of the lowest price generic of amoxicillin $500 \mathrm{mg}$ capsule for one week's treatment of pneumonia which costs 0.1 days' salary in Jordan which was highly affordable [24] and less than one days' salary in Ethiopia, Tanzania and Nigeria [4]. However, even with these diseases, affordability was largely dependent on choice of therapeutic class, types of products selected, and prescribing habit. For example, unskilled health worker would pay 4.63 and more than 3 days salary when he was prescribed and dispensed amoxicillin-clavulanic acid $(1 \mathrm{gm})$ and clarythromycin 500 $\mathrm{mg}$ respectively. However in the private pharmacies it was even slightly higher (4.69 and 3.37 respectively). This finding consistent with the results of study conducted to evaluate affordability using ceftriaxone injection for one week treatment of pneumonia in Nigeria and found to cost 18.80 days' wages which is unaffordable [4].

However, despite that affordability was shown for many studied conditions, but still affordability of medicines remains a major problem for Sudan. For example, although diabetes in Sudan is believed to have one of the highest mortality rates for a non-infectious disease, and $10 \%$ of adult patient deaths in hospitals were caused by diabetes 
Citation: Elhassan SM, Elhassan GO, Alfadl AA, Sirelkhatim SA, Alfarouk KO (2016) Evaluation of Drug Affordability in Khartoum State, Sudan. J Pharmacovigilance 4: 191. doi:10.4172/2329-6887.1000191

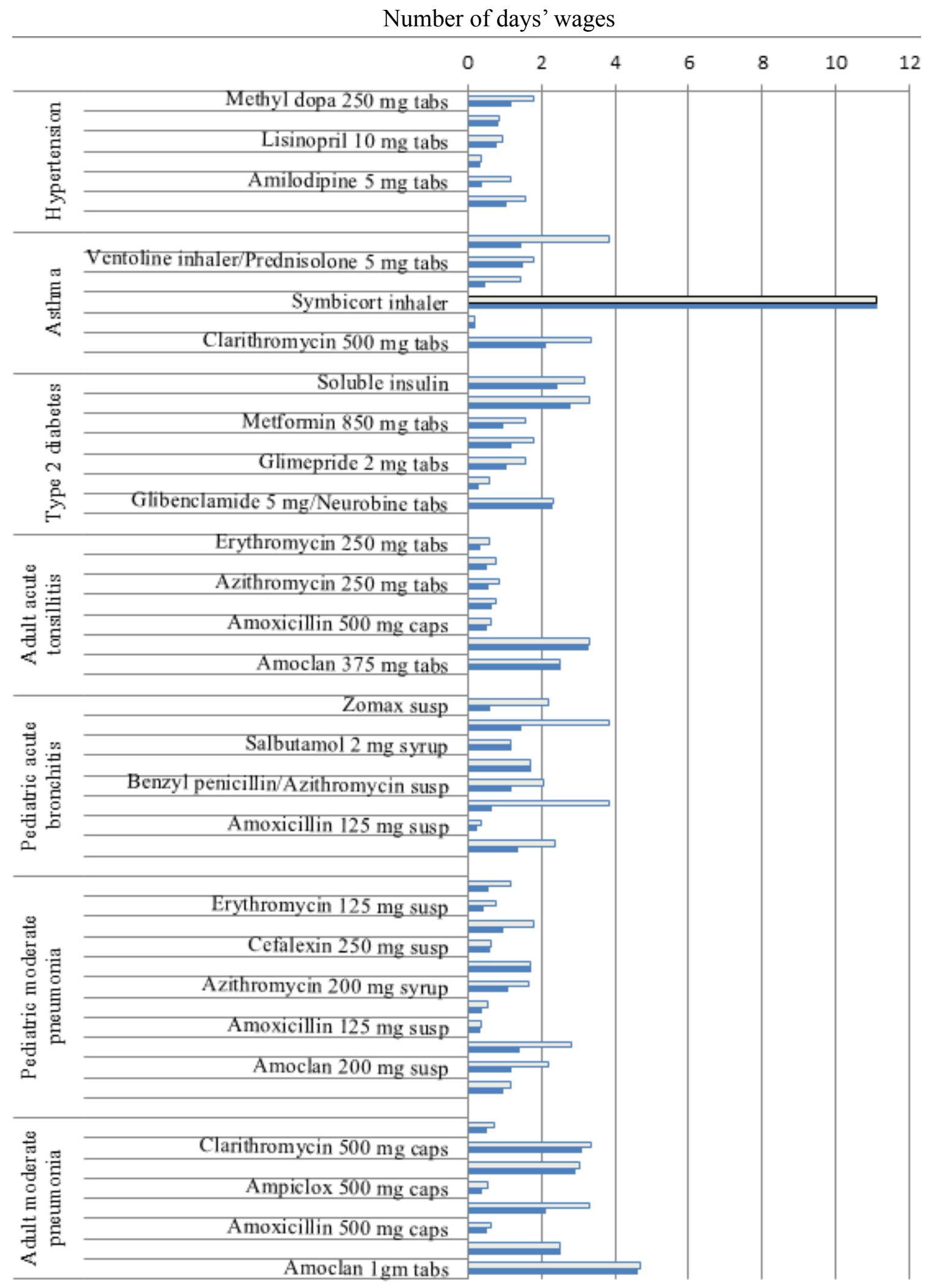

$\square$ Private $\quad$ Public

Figure 1: Affordability of treatment for the seven selected diseases in the public and private sectors. 
Citation: Elhassan SM, Elhassan GO, Alfadl AA, Sirelkhatim SA, Alfarouk KO (2016) Evaluation of Drug Affordability in Khartoum State, Sudan. J Pharmacovigilance 4: 191. doi:10.4172/2329-6887.1000191

Page 4 of 6

\begin{tabular}{|c|c|c|c|}
\hline \multirow{2}{*}{ Disease } & \multirow{2}{*}{ Regimen } & \multicolumn{2}{|c|}{ Total Cost (USD) } \\
\hline & & Public & Private \\
\hline \multicolumn{4}{|c|}{ Adult moderate pneumonia } \\
\hline & Amoclan $1 \mathrm{gm}$ tabs bid for 7 days & 11.5 & 11.6 \\
\hline & Amoclan 375 mg t.d.s for 5 days & 6.2 & 8.2 \\
\hline & Amoxicillin 500 mg caps t.d.s. for 5 days & 1.3 & 1.6 \\
\hline & Amoxicillin $500 \mathrm{mg}$ caps+clavulanic acid $125 \mathrm{mg}$ t.d.s. for 7 days & 5.2 & 8.2 \\
\hline & Ampiclox $500 \mathrm{mg}$ caps 6 hrly for 5 days & 1.0 & 1.3 \\
\hline & Cefixime caps o.d.+Trifed tabs tab t.d.s+antistin tab bid & 7.2 & 7.5 \\
\hline & Clarithromycin $500 \mathrm{mg}$ bid for 7 days & 7.7 & 8.4 \\
\hline & Erythromycin $250 \mathrm{mg}$ tabs 6 hourly for 5 days. & 1.3 & 1.8 \\
\hline \multicolumn{4}{|c|}{ Pediatric moderate pneumonia } \\
\hline & Amixime susp $100 \mathrm{mg}$ o.d for 7 days & 2.5 & 3.0 \\
\hline & Amoclan $200 \mathrm{mg} \mathrm{b.d} \mathrm{for} 5$ days & 3.0 & 5.4 \\
\hline & Amoclan $400 \mathrm{mg}$ for 5 days & 3.6 & 7.0 \\
\hline & Amoxicillin $125 \mathrm{mg} 5 \mathrm{mg} / 8 \mathrm{hrs} / 5$ days & 0.9 & 1.0 \\
\hline & Amoxicillin $250 \mathrm{mg} 5 \mathrm{mg} / 8 \mathrm{hrs} / 5$ days & 1.0 & 1.3 \\
\hline & Azithromycin $200 \mathrm{mg}$ syrup. $10 \mathrm{mg} / \mathrm{kg} /$ day for 3 days. & 2.8 & 4.1 \\
\hline & Cefaclor 125 mg t.d.s.for 7 days. & 4.3 & 4.3 \\
\hline & Cefalexin 250 mg suspension & 1.6 & 1.6 \\
\hline & Co Amoxiclav 156 mg t.d.s for 5 days & 2.5 & 4.4 \\
\hline & Erythromycin 125 mg 5 ml every 6 hrs. & 1.1 & 2.0 \\
\hline & Erythromycin 250 mg 40 mg/kg every 6 hrs. & 1.5 & 3.0 \\
\hline \multicolumn{4}{|c|}{ Pediatric acute bronchitis } \\
\hline & Amoclan susp $200 \mathrm{mg}+$ cough sedative for 5 days & 3.4 & 5.9 \\
\hline & Amoxicillin 125 mg 5 ml/8 hrs for 5 days. & 0.7 & 1.0 \\
\hline & $\begin{array}{l}\text { Benzyl penicillin } 1000000 \mathrm{IU} 6 \text { hrly for } 24 \text { hrsthydrocorizone } 10 \mathrm{mg} / \mathrm{kg} 6 \\
\text { hourly+ventoline nebulizer } 1 \mathrm{ml} 4 \text { hourly. }\end{array}$ & 1.7 & 9.5 \\
\hline & Benzyl penicillin for 24 hrs+azithromycin suspension & 3.0 & 5.1 \\
\hline & Cefaclor 125 mg t.d.s.for 7 days & 4.3 & 4.3 \\
\hline & Salbutamol 2 mg syp+antistin syp b.d & 3.0 & 3.0 \\
\hline & Ventoline per nebulizer $1 / 2$ cc 3 doses+hydrocortisone $100 \mathrm{mg}$ inj & 3.6 & 9.5 \\
\hline & Zomax susp & 1.6 & 5.4 \\
\hline \multicolumn{4}{|c|}{ Adult acute tonsillitis } \\
\hline & Amoclan $375 \mathrm{mg}$ for 5 days & 6.2 & 6.2 \\
\hline & Amoclan 625 mg t.d.s for 7 days & 8.2 & 8.2 \\
\hline & Amoxicillin 500 mg caps t.d.s for 5 days. & 1.3 & 1.6 \\
\hline & $\begin{array}{l}\text { Amoxicillin } 500 \mathrm{mg} \text { caps t.d.s for } 5 \text { days+metromidazole } 250 \mathrm{mg} \text { tabs t.d.s. for } \\
7 \text { days. }\end{array}$ & 1.6 & 2.0 \\
\hline & Azithromycin $250 \mathrm{mg} 2$ tab/day for 3 days. & 1.5 & 2.1 \\
\hline & Azithromycin 500 mg 1 tab/day & 1.3 & 2.0 \\
\hline & Erythromycin $250 \mathrm{mg}$ tabs 6 hourly for 5 days. & 0.8 & 1.5 \\
\hline \multicolumn{4}{|c|}{ Type 2 diabetes } \\
\hline & Glibenclamide 5 mg o.d.+neurobine o.d (30+30 tabs) & 5.7 & 5.7 \\
\hline & Glibenclamide 5 mg/day (30 tabs) & 0.7 & 1.5 \\
\hline & Glimepride 2 mg tabs o.d. (30 tabs) & 2.6 & 3.9 \\
\hline & Metformin 500 mg tabs t.d.s. (90 tabs) & 3.0 & 4.4 \\
\hline & Metformin 850 mg tabs b.d. (60 tabs) & 2.5 & 3.9 \\
\hline & Mixtard insulin (1 vial per month) & 6.9 & 8.2 \\
\hline & Soluble insulin (1 vial per month) & 6.1 & 7.9 \\
\hline \multicolumn{4}{|l|}{ Asthma } \\
\hline & Clarithromycin $500 \mathrm{mg}$ tabs bid for 7 days & 5.2 & 8.4 \\
\hline & Salbutamol $4 \mathrm{mg}$ tabs every day. & 0.5 & 0.5 \\
\hline & Symbicort inhaler & 27.5 & 27.5 \\
\hline & Ventoline inhaler & 1.2 & 3.6 \\
\hline & Ventoline inhaler+prednisolone $5 \mathrm{mg} 6$ tabs per day for 7 days & 3.7 & 4.4 \\
\hline & Ventoline per nebulizer $1 / 2$ cc 3 doses+hydrocortisone 100 mg injection & 3.6 & 9.5 \\
\hline \multicolumn{4}{|c|}{ Hypertension } \\
\hline & Amilodipine 10 mg o.d. (30 tabs/month) & 2.6 & 3.9 \\
\hline & Amilodipine 5 mg o.d. (30 tabs/month) & 1.0 & 3.0 \\
\hline & Atenolol 50 mg o.d (30 tabs/month) & 0.8 & 0.9 \\
\hline
\end{tabular}




\begin{tabular}{|l|l|l|}
\hline Lisinopril $10 \mathrm{mg}$ (30 tabs/month) & 2.0 & 2.3 \\
\hline LoscarH o.d. (30 tabs/month) & 2.1 & 2.1 \\
\hline Methyl dopa $250 \mathrm{mg}$ t.d.s (30 tabs/month) & 3.0 & 4.4 \\
\hline
\end{tabular}

Table 1: Cost of treatment for the seven selected diseases in the public and private sectors.

[20], this study showed that the unaffordable treatments in the public sector include insulin both soluble and mixtard (2.44 and 2.78 days' wages), metformin $500 \mathrm{mg}$, Glimepride $2 \mathrm{mg}$ tabs (1.06 days' wages), and prescriptions containing glibenclamide and high priced vitamine $\mathrm{B} 1, \mathrm{~B} 6$, and B12 formulations. In the private pharmacies all of these are unaffordable with a higher cost than the public sector in addition to the unaffordability of metformin $850 \mathrm{mg}$ (1.59 days' wage). Simialr finding was observed with hypertension which is also one of the top ten leading causes of deaths in hospitals in Khartoum State [20]. The affordability in hypertension treatment varies according to type of drug used and whether it is the lowest generic substitute or not. Additionally if two or more medicines are needed to control the case it becomes slightly or strongly not affordable according to the drug added or the co-existing disease. It was observed that amilodipine $10 \mathrm{mg}$ and methyl dopa $250 \mathrm{mg}$ tabs both unaffordable in public (1.06, 1.19 days wages) and private pharmacies (1.59, 1.78 days' wages), respectively. Again with asthma treatment, if prescribing pattern changes, or if such type of treatment is needed, we can have more than 11 days' salary to afford medicines like symbicort, and it costs 1.49 days salary to be treated with a combination of salbutamol inhaler plus prednisolone. Also if the originator salbutamol inhaler is prescribed and/or dispensed as the case in the private pharmacies used for the assessment, then 1.45 days' salary is needed. If a ventoline nebulizer plus hydrocortisone injection is prescribed it will need 1.45 and 3.83 days' wages depending on the place the medicines are purchased from public or private pharmacies, respectively. This may be due to lack of lower price substitution policy due to lack of incentive policy for that. However, situation is still better than some other developing countries as shown in study conducted in Ethiopia which revealed that even with the lowest price generic of salbutamol $100 \mathrm{mcg} /$ doses inhaler to afford one month treatment of asthma was more than one day's wage [4].

These above mentioned examples revealed that unaffordability in Sudan most probably is due to the fact that treatment guidelines and protocols to treat prevalent diseases are either not available or not fully enforced except the funded diseases such as malaria, tuberculosis and HIV infections. This has led to variation in prescribing habits and skills in addition to different ways to treat the same disease by using single or combination medicines from different therapeutic groups. Therefore, it is strongly believed that improvement in the rational use of medicines is likely to play an important future role. Interventions that have proved effective with this regard in developing countries include professional measures (e.g. essential drug lists; standard treatment guidelines; drug and therapeutics committees; problembased basic professional training; and targeted in-service training of health workers) [25] and financial measures (e.g. direct financial incentives) [26]. In addition, some other policies were suggested for cost containment and promotion of generics, and for promotion of public awareness like influencing the patient to ask for prescription of cheaper version of medicines [27-29]. Recently, a number of countries have used the results of medicine prices, availability and affordability surveys to inform and guide policies to improve access to medicines [30].

\section{Conclusion}

It could be concluded that absence of standard treatment guidelines that are of sound scientific bases and cost-effectiveness resulting in low quality prescribing and dispensing practices which had led to wide variations in the prescribing patterns for the assessed acute and chronic conditions. Some conditions were affordable when one medicine was prescribed, whereas, treatment of same condition was found to be unaffordable when more than one drug per prescription is prescribed and or dispensed; and affordability varies greatly according to the type of medicine prescribed its amount and whether the low generic price is purchased or not.

\section{References}

1. WHO/HAl (2008) Medicine Prices - A new approach to measurement, (2003 edn), Working draft for field testing and revision.

2. OECD (2009) Pharmaceutical pricing policies in a global market.

3. WHO (2000) Global comparative pharmaceutical expenditures with related reference information. Health Economics and Drugs EDM Series No. 3, Geneva.

4. WHO (2004) The world medicines situation, Geneva

5. Van Doorslaer E, O'Donnell O, Rannan-Eliya RP, Somanathan A, Adhikari SR et al. (2006) Effect of payments for health care on poverty estimates in 11 countries in Asia: an analysis of household survey data. Lancet 368: 13571364

6. Cameron A, Ewen M, Ross-Degnan D, Ball D, Laing R (2009) Medicine prices, availability, and affordability in 36 developing and middle-income countries: a secondary analysis. Lancet 373: $240-249$

7. OECD (1998) Drug spending in Organization for Economic Co-operation and Development (OECD) countries up by nearly a third since 1998, according to new OECD data.

8. Laing R, Waning B, Gray A, Ford N, Hoen E (2003) 25 years of the WHO essential medicines lists: progress and challenges. Lancet 361: 1723-1729.

9. Bennett S, McPake B, Mills A (1997) Private health providers in developing countries: serving the public interest? Zed Press, London.

10. Dror DM, Preker AS, Jakab M (2002) The role of communities in combating social exclusion.

11. WHO (2008) Access to medicines.

12. United Nations (1948) The universal declaration of human rights.

13. United Nations (1966) International covenant on economic, social and cultural rights. Geneva.

14. Wiedenmayer K (2004) Access to medicines. Medicine supply: Lessons learned in Tanzania and Mozambique. A capitalization report established in the frame of SDC back stopping mandate 2004 of the social development division's health desk. Swiss Tropical Institute. Swiss Centre for International Health.

15. Ali GKM, (2006) Accessibility of Medicines and Primary Healthcare: the impact of the RDF in Khartoum State. Nottingham Trent University.

16. Ali GKM (2009) Accessibility of medicines and primary health care: The impact of the revolving drug fund in Khartoum State. African Journal of Pharmacy and Pharmacology 3: 70-77.

17. El-Idrissi (2002) Health Economic Consultation in Sudan. WHO, Khartoum.

18. FIP (2009) Global pharmacy workforce report. The Hague, Federation Internationale Pharmaceutique (FIP).

19. WHO (2006) Using indicators to measure country pharmaceutical situations - Fact Book on WHO Level I and Level II monitoring indicators. World Health Organization, Geneva

20. $\mathrm{MoH}$ (2010) Annual health statistical report. National Ministry of Health (MoH) National Health Information Centre, Khartoum.

21. WHO/HAI (2008) Measuring medicine prices, availability, affordability and price components, ( $2^{\text {nd }}$ edn $)$, Geneva. 
Citation: Elhassan SM, Elhassan GO, Alfadl AA, Sirelkhatim SA, Alfarouk KO (2016) Evaluation of Drug Affordability in Khartoum State, Sudan. J Pharmacovigilance 4: 191. doi:10.4172/2329-6887.1000191

22. Niens LM, Brouwer WB (2009) Better measures of affordability required. Lancet 373: 1081-1082.

23. WHO (2011) The selection and use of essential medicines: report of the WHO Expert Committee, (including the $17^{\text {th }} \mathrm{WHO}$ model list of essential medicines and the 3rd WHO model list of essential medicines for children). WHO technical report series; no. 965. World Health Organization, Geneva.

24. Irbid, Zarqa, Karak (2007) Medicine prices, availability and affordability in Jordan: report of a survey conducted in 2004 in Amman, using the WHO/HAl price measurement methodology.

25. Laing R, Hogerzeil H, Ross-Degnan D (2001) Ten recommendations to improve use of medicines in developing countries. Health Policy and Planning 16: $13-20$

26. Riewpaiboon A (1998) Design and evaluation of an incentive scheme for promoting rational antibiotic prescribing in a provincial hospital in Thailand. Curtin University of Technology
27. Quick JD (2003) Ensuring access to essential medicines in the developing countries: a framework for action. Clin Pharmacol Ther 73: 279-283.

28. Kanavos P, Costa-Font J, Seeley E (2008) Competition in off-patent drug markets: Issues regulation and evidence. Economic Policy 23: 499-544.

29. Joncheere K, Rietveld AH, Huttin C (2002) Experiences with generics. In Drugs and Money, (7th edition), Edited by Dukes FM, Haaijer-Ruskamp CP Joncheere A, Rietveld $\mathrm{H}$. The Netherlands: Published on behalf of WHOEurope 101-110.

30. Cameron A, Ewen M, Auton M, Abegunde D (2011) The world medicines situation 2011. Medicine prices, availability and affordability. 